\title{
OS CADERNOS DE CAMPO DE ROGER BASTIDE
}

\author{
Roger Bastide’s Field Notebooks
}

Maria de Lourdes Patrini Charlon*

\begin{abstract}
RESUMO
Uma quantidade considerável de manuscritos, repertoriados em um inventário, constitui-se em um vasto campo de descobertas. Minha pesquisa se inscreve na análise dos "cadernos de campo", manuscritos de Roger Bastide. Entre os pesquisadores que chegaram ao Brasil nas primeiras décadas do século XX, ele foi um dos que mais tempo ficou entre nós e que fez do Brasil a fonte de todas as suas preocupações de estudioso e crítico. Sabemos que o "caderno de campo", utilizado como instrumento de pesquisa, revela, além de uma competência de observação do "outro", uma competência de criação estética, com eficácia literária, no modo de apresentação dos dados. Conforme venho constatando no decorrer desse meu trabalho, os cadernos de campo de Roger Bastide representam um conjunto de escritura autográfica preparatória no seio do qual se encontram expostos os passos de uma produção e de um itinerário realizados pelo pesquisador na Europa, no Brasil e na África.
\end{abstract}

Palavras-chave: manuscritos; caderno de campo; Roger Bastide; escritura de campo.

\begin{abstract}
A considerable number of manuscripts, listed in an inventory, constitute a vast field of discovery. My research falls into the category of analysis of "field notebooks", manuscripts by Roger Bastide, one of the researchers who stayed the longest in our country, among those who came to Brazil in the first decades of the twentieth century, and who made Brazil the source of all his interests as a scholar and critic. We know that the "field notebook" used as a research tool, not only shows an ability to observe the "other", but in the way it presents data, also allows aesthetic creation, in an efficient literary mode. As I have been observing throughout my
\end{abstract}

* Professora associada da Universidade Federal do Rio Grande do Norte - UFRN. 
research, Roger Bastide's field notebooks represent a set of preparatory autographic writing, at the heart of which we can follow the researcher's steps in Europe, Brazil and Africa.

Key-words: manuscripts; field notebook; Roger Bastide; field writing.

As análises que venho realizando sobre os cadernos de campo de Roger Bastide ${ }^{1}$, assim como a pesquisa sobre práticas de escritura - a escritura pessoal, próxima do diário íntimo e da autobiografia, da escritura profissional (carnês de viagem, carnês de escritores e etnólogos) - buscam investigar a experiência de pesquisa dos antropólogos através dos respectivos cadernos de campo, em que observações e narrativas relatadas e registradas sobre o "outro" se cruzam com o registro pessoal do pesquisador.

O meu interesse pelo caderno de campo, suporte e instrumento de trabalho de antropólogos, se justifica enquanto material que contém uma base documental de trabalho, isto é, uma escritura que põe em cena o pesquisador, investimento do "eu" no discurso, sua implicação nas observações e na construção do texto etnográfico. A aventura da escritura corresponde a motivações particulares dos autores, assim como "[...] à des épisodes qui, d'une façon ou d'une autre, ont influencé la vie de celui qui écrit;" (CHARTIER, 2001, p. 828).

Sabemos também que a descrição etnográfica é, de certa forma, o resultado de muitos fatores: personalidade do pesquisador, seu encontro com o "outro", suas escolhas estratégicas na apresentação de detalhes, a construção de seu texto etc. Em seu artigo, "De l'exploitation des archives de terrain", Jan-Lodewijk Grootaers corrobora nesse sentido, ressaltando que o estudioso deve conduzir o seu trabalho levando em conta esses fatores e afastar a posição ingênua que consiste em conceber e defender a observação como uma progressão direta e sem equívocos à produção de conhecimentos. O estudo em Ciências Humanas requer o caráter fundamentalmente dialógico, pois "le travail de terrain ethnografique est um processus inter-

1 Em agosto de 2003, iniciei um trabalho de pesquisa sobre os cadernos de campo de antropólogos franceses (projeto de pesquisa de pós-doutorado - E.H.E.S.S., Paris). Além da participação em congressos e dos seminários que ministrei durante o pós-doutorado, publiquei artigos sobre essa pesquisa: Les carnets de terrain de Roger Bastide. Cahiers du Brésil Contemporain. Paris, E.H.E.S.S. e CRBC, n. 55/56. 2004/2005; Os cadernos de campo de Roger Bastide: entrecruzamentos múltiplos. Revista Brasileira de Literatura Comparada-ABRALIC, n. 9, 2006 e Na escritura de campo uma voz "en cachette". Sigila - revue transdisciplinaire franco-portuguese, Paris: Printemps-été, 2006, entre outros. 
subjectif et la compréhension ethnologique est le résultat d'une démarche herméneutique" (GRAHIVA, n. 30/31, p. 74)2 que, partindo de uma nova concepção do tempo e da narrativa, da relevância que dá à contribuição do leitor, da importância da capacidade compreensiva, da fusão de horizontes aponta para a valorização do receptor e abertura para a alteridade: operação dialógica entre obra e leitor, leitura vista como experiência, ação, acontecimento, evento. $\mathrm{O}$ autor do artigo acima citado, retomando em outros termos a fórmula de Laplantine escreve, complementando, assim, o procedimento adotado nesse estudo: "[...] les notes ethnographiques ne sont jamais de simples dépôts d'observations faites sur place que seraient ensuite converties en article ou monographie par le véritable travail d'écriture; ces notes font partie, dès leur rédaction, de cette textualisation en chaîne qui caractérise l'ethnologie"3 (p. 76).

Estudiosos de diferentes áreas do conhecimento nos informam que, até o início dos anos 90, havia uma falta de interesse pela escritura de campo - pela produção e textualidade de notas etnológicas, pelo "hors-texte" em relação ao interesse voltado para o "texte representation" da monografia ${ }^{4}$. Com os avanços das pesquisas, inaugura-se um tempo de transformações de pontos de vista. Abrem-se, assim, espaços para o estudo de notas, de rascunhos, entrevistas, diários, correspondências e relatórios. A história cultural tem mostrado, nestes últimos anos, o interesse heurístico de uma articulação entre os estudos dos suportes da produção textual impressa e os estudos de suas leituras ${ }^{5}$.

Nos últimos anos, na Europa e nos Estados Unidos, mas também no Brasil, estudiosos de diferentes áreas têm se interessado pelos apontamentos e rascunhos de pesquisadores e de escritores que foram produzidos concomitantemente com suas obras ou que as acompanharam. Entre os "autores" das Ciências Humanas, pensemos nos cadernos de campo de Lévi-Strauss, Em

2 GROOTAERS, Jan-Lodewijk. De l'exploitation des archives de terrain. Une textualisation em chaîne. In: GRAHIVA - Revue d'Histoire et d'Archives de l'Anthropologie. Paris: Jean Michel Place, 2001/2003.

3 "Retomando em outros termos a fórmula de Laplantine", o autor do artigo se refere à obra de: LAPLANTINE, François. La description ethnographique. Paris: Editions Nathan, 1996.

4 Expressões usadas por Mondler Kilani em: Les anthropologues et leur savoir: du terrain au texte. In: ADAM, J. M.; BOREL, M. J.; CALAME, C.; KILANI, M. Le discours anthropologique. Description, narration, savoir. Lausanne: Editions Payot, 1995, p. 65-100.

5 Nesse sentido, merecem destaque os trabalhos desenvolvidos por Roger Chartier. Outros paradigmas interpretativos se apresentam nos estudos de P. Lejeune e Daniel Fabre. 
marge de "Tristes tropiques" ", em Journal d'ethnographe, de Malinowski, em L'Afrique fantôme, de Michel Leiris; quanto aos escritores, citaremos, entre outros, os carnês de trabalho (carnets de travail) de Gustave Flaubert, os carnês de pesquisa (carnets d'enquête) de Emile Zola, as cadernetas de João Guimarães Rosa, as notas e fragmentos de Euclides da Cunha.

$\mathrm{Na}$ França, alguns estudiosos se interessam pelos suportes, pela materialidade dos objetos da escritura: carnês, cadernos, diários, álbuns e registros. Analisam as características concretas dos manuscritos ou a própria escritura enquanto prática. Existem inúmeras e diversas abordagens das práticas de escritura: os trabalhos de genética textual dedicam-se a decifrar manuscritos e rascunhos e abrangem o conjunto mais ou menos desenvolvido dos "documentos de redação" de um autor, o que, na linguagem comum, é chamado de "manuscritos da obra". A "genética textual" é, portanto, aquele tipo de investigação que interroga os textos a partir de sua fabricação, de sua gênese.

As escolas paleográficas italianas e espanholas, além do deciframento e da erudição, abriram-se para a abordagem social e cultural das práticas da escritura manuscrita (qualquer suporte, da pedra ao papel). A história cultural privilegia a articulação entre o estudo dos suportes da produção textual impressos e o estudo de suas leituras. Nesse método de análise, podemos destacar também os estudos de Roger Chartier. Entre os estudos literários dedicados à análise do diário íntimo, das escrituras não letradas, citaremos os de Philippe Lejeune. Por fim, etnólogos se debruçaram sobre as escrituras do cotidiano, também chamadas de escrituras ordinárias, à imagem dos trabalhos realizados por Daniel Fabre.

\section{O caderno de campo}

O estudo do caderno de campo situa-se aqui na perspectiva da literatura, da história, da antropologia cultural e da hermenêutica. Privilegiando o conteúdo antropológico e os aspectos estéticos, procuro também identificar e analisar as imagens e as representações do Brasil que os pesquisadores

6 LÉVI-STRAUSS, Claude. Oeuvres. Paris: Éditions Gallimard, Bibliothèque de La Pléiade, 2008. 
constroem em seus cadernos. Chamo também a atenção para o campo da comunicação, situado numa reciprocidade relacional, e para a elocução enquanto produtora de sentido.

Com as transformações e a evolução das ciências literárias e sociais nas últimas décadas, podemos destacar o surgimento de novos paradigmas de interpretação, inspirados na semântica da ação, na fenomenologia e na tradição hermenêutica. Com efeito, estudiosos de diversas disciplinas estudam o homem a partir de uma atitude epistemológica na qual a influência da hermenêutica contemporânea é evidente (GADAMER, 1994). Um dos filósofos que deu origem a essas mudanças de interpretação foi Paul Ricoeur (1995), com seus trabalhos sobre a escritura da história e a poética do saber, ideias que sistematizou em Tempo e narrativa.

A hermenêutica literária é uma releitura da história que parte de uma nova concepção do tempo e da narrativa, sobretudo pela importância dada à contribuição do leitor. A importância atribuída à capacidade de compreensão, através da fusão de horizontes, visa à valorização do receptor e à abertura para a alteridade. Assim, o sentido resulta da operação dialógica entre a obra e o leitor, o que quer dizer que a leitura é percebida como uma experiência, uma ação, um acontecimento.

Portanto, no que concerne à interpretação, privilegio o campo das linguagens, das representações e das culturas, abordagens que me parecem mais adequadas aos objetivos de meu trabalho. Incluo certos autores das sociologias dos sistemas simbólicos, como Norbert Elias, e filósofos e historiadores como Michel Foucault. Os autores que usam a hermenêutica para a interpretação dos signos enquanto elementos simbólicos de uma cultura e dos sistemas de pensamento, tendo o sujeito como ponto central, servirão de guias para as análises e as interpretações dos dados.

Aos pontos de vista dos autores já citados, acrescentarei os de Clifford Geertz. Por meio de uma análise da escritura, ele nos mostra que alguns dos mais conhecidos antropólogos desenvolveram estratégias discursivas complexas para que, junto com eles, pudéssemos penetrar profundamente no campo. Geertz (1996) afirma ainda que, para que se possa pensar a etnografia como uma prática de pesquisa, é preciso estabelecer vínculos, selecionar os informantes, retranscrever textos, detectar genealogias, manter um diário.

No âmbito desta pesquisa, interesso-me pelos cadernos de campo enquanto base de dados do trabalho do antropólogo em que o próprio pesquisador entra em cena. Procedo, portanto, à análise de sua presença nesse 
discurso, interrogo-me sobre sua implicação pessoal nas observações, na construção de hipóteses, nas escolhas teórico-metodológicas, bem como nas figurações de caráter estético.

Os cadernos de campo constituem documentos muito ricos. Entendemos, no entanto, que enquanto tais só revelem todo o seu sentido quando iluminados pela leitura de outros documentos. O conteúdo do caderno de campo comporta por certo dados coletados, observações e comentários, sobre o objeto de estudo do pesquisador, mas também dados pessoais sobre $\mathrm{o}$ desenrolar da estada em campo. Contudo, o caderno nunca será uma história completa, nem de seu percurso profissional, nem de sua história pessoal, nem um autorretrato fiel. O implícito, a descontinuidade, a irregularidade, bem como lacunas, sempre estarão presentes.

A análise dos cadernos de campo dos antropólogos não nos informará apenas sobre o trabalho de campo propriamente dito, sobre a observação e a coleta de dados, mas também sobre a maneira particular que cada um tem de organizar de modo criativo os resultados que obtiveram. Ao privilegiar o conteúdo antropológico e os aspectos estéticos, esta pesquisa também visa avaliar e traduzir as imagens e representações que os pesquisadores colheram no campo.

Nesse sentido, minhas observações se concentram nos movimentos de distanciamento e de envolvimento do pesquisador em relação ao seu estudo, mas também nas notas de ordem pessoal que às vezes o "outro" exige. Meu interesse se volta para os "cadernos de campo" enquanto base documental de trabalho, isto é, uma escritura que põe em cena o pesquisador, investimento do "eu" no discurso - produto híbrido e fértil - que possibilita a análise dessa presença no discurso, sua implicação nas observações, na construção das hipóteses. No meu entender, nesse trabalho, os cadernos de campo revelam uma prática de escritura como ação - exercício da profissão -, mas também como memória - base de dados do pesquisador.

\section{Algumas prefigurações...}

A denominação "cadernos" vem dos cadernos de viagem anotados pelos viajantes dia após dia. Um dos primeiros "diários íntimos” escritos 
e publicados pertence a um funcionário inglês, Samuel Pepys. No terreno do gênero autobiográfico, podemos citar alguns exemplos: as Confissões, de Santo Agostinho (354-430), os Ensaios de Montaigne (1533-1592), onde o autor relata suas experiências e suas reflexões, as Confissões de Jean-Jacques Rousseau (1712-1778). Escritores como Benjamin Constant e Chateaubriand (século XIX), para citar apenas estes dois nomes bem conhecidos, escreveram diários íntimos e memórias. Desde o começo do século XX, escritores como André Gide, Michel Leiris e Simone de Beauvoir produziram escritos autobiográficos. Para avançar um pouco mais no tempo, em 1980, enquanto escrevia Para sair do século XX, Edgar Morin escreveu um "diário" sobre a realização do livro. Esse "diário" foi publicado com o título Journal d'un livre.

Por muito tempo a biografia histórica foi considerada um gênero menor e por isso não foi levada em conta pela maioria dos historiadores do século XIX, nem por aqueles do século XX, com algumas exceções notáveis, como Martin Luther. Um destino, de Lucien Febvre (1928). Contudo, esse gênero foi reabilitado recentemente por alguns historiadores dos Annales: Jacques Le Goff dedicou um estudo a São Luís (1996) e depois outro a São Francisco de Assis (1999). Nesse caso, o historiador retraça uma vida como se fosse testemunha de uma sociedade, de um modo de vida. É também sob essa ótica que Carlo Ginsburg descreve o universo das pessoas comuns, como o de um moleiro do século XVI, em O queijo e os vermes (1976). No que se refere à história política contemporânea, a perspectiva é outra e o desafio, maior, pois é aí onde o historiador tem de articular a existência de alguém com as referências da "grande" história.

Nesse gênero, a variedade das práticas de escritura é evidente, e é onde incluímos os usos, as intenções, os objetivos, bem como suportes e denominações. A partir do século XVII e até hoje serão mencionados diários íntimos, diários literários, cadernos de escritor, biografias, biografias históricas, autobiografias, memórias, relatos etnológicos, diários de pesquisa, diários etnográficos e cadernos de campo. No que se refere ao caderno de campo, a partir do começo do século XX os antropólogos foram os primeiros a dar esse exemplo com seus cadernos ou diários de campo, elaborados durante suas pesquisas de campo. Podemos citar Un Journal d'Ethnographe, de Bronislaw Malinowski, escrito entre 1914 e 1920 e publicado em 1967. Durante sua viagem às ilhas melanésias, manteve um diário. Na introdução 
a essa publicação, Remo Guidieri sublinha que "Com efeito, encontramos no testemunho três tipos de ambiguidades: uma relativa ao papel ('espião-intruso'); outra relativa à relação (a pergunta - especular, por sinal - é: 'quem é você?'); e uma terceira relativa à experiência ('entendi, aprendi o suficiente?'). Malinowski e Evans-Pritchard representam sobretudo a última. Os relatos deles são relatos da perplexidade (...)". (p. 13 da ed. francesa). Nesse sentido, sublinha Geertz:

Escrever um texto que possa ser ao mesmo tempo expressão de um sentimento íntimo e um relatório distanciado é quase tão difícil quanto satisfazer as duas exigências durante o trabalho de campo $[. .$.$] como ser viajante e cartógrafo ao mesmo tempo$ (GEERTZ, 1996, op. cit., p. 18).

Alguns estudiosos em Ciências Humanas fizeram dos apontamentos provenientes da observação do campo um verdadeiro método de trabalho, estruturado, no qual a confrontação entre o sujeito e o outro ocupa o lugar central. É preciso manter negociações entre si e os outros. Publicaram-se muitas "narrativas", mas poucos verdadeiros cadernos (Malinowski, Leiris). Os cadernos de campo sobre seus suportes originais são pouco estudados desse ponto de vista. Será que os textos dos antropólogos que foram ao Brasil dizem que eles estiveram lá? Como apreender as diferenças de origem dos textos encontrados nos arquivos? Dos antropólogos franceses cujos cadernos de campo escolhi estudar, o primeiro a cujos manuscritos tive acesso foi Roger Bastide.

\section{Roger Bastide no "país dos contrastes"}

"L'harmonie existe jusque dans le contraste, le contraste continue jusque dans la réconciliation des antagonismes"7.

Roger Bastide

7 BASTIDE, Roger. Brésil, terre des contrastes. Paris: Hachette, 1957, p. 13. Citado em "Les Années brésiliennes de Roger Bastide, par Maria Isaura Pereira de Queiroz. Bastidiana, n. 1, 1993, p. 33. 
Roger Bastide foi um dos antropólogos franceses que esteve no Brasil nas primeiras décadas do século XX realizando estudos. Em 1938, ano de sua chegada, assumiu a cátedra de Sociologia na Universidade de São Paulo, recentemente fundada. A partir daquele momento, seus campos de atuação foram a França, o Brasil e a África. Suas buscas e escolhas confirmam seu engajamento à sua problemática central sobre os contratos culturais e sistemas simbólicos. Entre os pesquisadores franceses que aqui estiveram, citaria: Claude Lévi-Strauss, Roger Bastide, Fernand Braudel, Lucien Febvre. Entre eles, Roger Bastide foi um dos que mais tempo ficou entre nós e que fez do Brasil a fonte de todas as suas preocupações de estudioso e crítico. Ele chegou ao Brasil num momento em que a urbanização do país avançava rapidamente, em que a cidade de São Paulo estava em pleno desenvolvimento:

Desde sua chegada ao Brasil, devorou com avidez a literatura, a poesia e a sociologia brasileiras, tornando-se assim um crítico militante e um estudioso que pesou de maneira notável na interpretação de fatos, ideias e obras, na condição de colaborador constante dos jornais - registrando livros novos, comentando exposições, debatendo teorias [...] (CÂNDIDO, 1993, p. 99-104).

Escritores, poetas e intelectuais brasileiros, alguns deles também ex-alunos, escreveram sobre a atuação de Roger Bastide como professor, pesquisador e crítico. Nesses escritos, observamos a intenção primeira de apresentar e ressaltar o papel do professor como o responsável pela formação da primeira geração de sociólogos da Universidade de São Paulo.

Em 1943, Drummond de Andrade ${ }^{8}$ escreve a Bastide felicitando-o pela "fecunda ação de presença em nosso meio universitário" e, nessa mesma carta, o poeta vai igualmente lhe agradecer pela leitura feita aos seus poemas:

[...] vejo que o senhor leu o poeta com uma simpatia humana que lhe valorizou as produções e as situou dentro de estados

8 Neste artigo, contento-me em citar passagens breves da correspondência e dos cadernos de campo. Como se trata de um material inédito, estou autorizada a publicar trechos não muito longos, e se torno públicas algumas passagens, faço-o com a autorização da direção do IMEC. Estas passagens foram publicadas em: A presença de Câmara Cascudo nos manuscritos de Roger Bastide. Scriptoria III-ensaios de Literatura. Natal: EDURN, UFRN/PPGEL, 2008, p. 163-175. 
psicológicos e emocionais, tirando daí o maior interesse da crítica. [...] Sua compreensão e simpatia pelos poetas valem assim como um elemento precioso na confusão que os jornais lançam em torno da poesia e que tanto a afastam da grande massa de leitores.

Em 1. ${ }^{\circ}$ de junho de 1946, o mesmo emissor vai se referir ao leitor e crítico Bastide assinalando que os novos poetas brasileiros encontraram nele um leitor "cheio de sensibilidade e compreensão servido por uma aparelhagem crítica de primeira ordem". Desde que chegou ao Brasil, Roger Bastide se interessou pela Literatura Brasileira e fez desse interesse uma fonte de conhecimento através da leitura das obras e da correspondência que manteve de forma sistemática com seus autores.

Enquanto esteve conosco e mesmo depois de sua volta para a França, publicou livros e produziu uma variedade extraordinária de artigos e resenhas. Crítico militante, colaborador constante de jornais e revistas brasileiros, alguns de seus artigos e livros tornaram-se referências obrigatórias para os estudos da Literatura e das Ciências Sociais. Antonio Candido, em "Roger Bastide e a literatura brasileira"10, coloca em distinção o artigo que Bastide escreveu sobre Machado de Assis e assinala igualmente sua influência sobre Mário de Andrade, "cujas ideias sobre a gênese da literatura popular foram certamente redefinidas graças a ele". Numa carta ${ }^{11}$ dirigida ao "meu caro professor Roger Bastide", Mário de Andrade agradece o estudo feito por Bastide sobre sua produção poética: "Tenho relido várias vezes a vossa análise e em todas elas me toma o deslumbramento. É com efeito a mais luminosa das recompensas para o artista que se pretende verdadeiro, se ver assim tão compreendido e tão lucidamente interpretado" (Araraquara - SP, 1943, carta manuscrita).

A maneira de ser e as nuances da personalidade do intelectual Bastide estão por todo o Brasil, guardadas na lembrança dos alunos ${ }^{12}$, amigos

9 As citações de trechos das cartas foram transcritas de acordo com os originais.

10 CANDIDO, Antonio. Roger Bastide e a literatura brasileira (p. 17). Recortes. São Paulo: Companhia das Letras, 1993, p. 99-104.

11 Esta carta foi entregue, em mãos, para R. Bastide, pela Profa. Gilda de Melo e Souza.

12 Encontrei no arquivo dos manuscritos de Roger Bastide além da vasta correspondência que ele manteve com seus alunos (alguns deles, futuros colegas de profissão), trabalhos, projetos e dados de pesquisa de campo realizados pelos seus alunos. 
e colegas de profissão. Em permanente contato com os poetas, escritores e intelectuais do país, foi se interessando pela cultura do povo brasileiro, sua religiosidade, suas festas e rituais, suas danças, suas representações. Por sua forma de lidar com significados e de viver essa cultura no seu cotidiano, foi ensinando e aprendendo, colhendo frutos daqui e de lá, ouvindo com atenção uma multiplicidade de vozes com as quais Bastide soube muito bem manter uma interlocução constante e solidária. Buscava obstinadamente o conhecimento, queria aprender sobre o Brasil e o seu povo, estando sempre disposto a discutir para chegar à compreensão do "outro". A atividade crítica de Bastide em relação à nossa arte e à nossa literatura foi constante e marcante. O rigor científico dos métodos, presente em seus trabalhos, foi apreciado pelos intelectuais brasileiros. Assim escreveu (carta, 1947) Aníbal Machado ao antropólogo:

Aprecio devidamente a importância de seus trabalhos [...] principalmente, porque sinto neles o calor da presença de quem se comove diante daquilo mesmo que estuda e interpreta! Como tem sido preciosa a sua contribuição ao conhecimento do que há de mais esquivo no Brasil subterrâneo.

Trabalhador infatigável, colaborador dos jornais e das revistas, sempre comentando acontecimentos artísticos e culturais, exercendo como prática diária o debate teórico, manteve com estudantes e pesquisadores $\mathrm{o}$ que Paul Arbousse-Bastide chamara de uma "reciprocidade igualitária". Escreveu, atuou e empenhou-se na análise dos problemas da cultura brasileira, tornando-se um estudioso múltiplo. Enfim, como afirma o professor de literatura em seu citado artigo, Bastide foi "um dos poucos a usar com segurança e felicidade a difícil combinação entre literatura e sociologia" (p. 99).

O primeiro texto que Bastide escreveu no Brasil, "Meditações brasileiras sobre um mercado de São Paulo", publicado em julho de 1938, em Dom Casmurro, mostra as preocupações aculturativas do autor e seu espanto diante de tal mistura de raças. No mesmo ano, ele publica um estudo sobre as relações inter-raciais e uma reflexão sobre pintura e misticismo. Em 1940, aparece outro artigo: "Psicanálise do Cafuné", título retomado um ano mais tarde para seu primeiro livro brasileiro. 
Bastide sempre soube como acatar e debater teorias e, inclusive, estabelecer, "com homens do porte de Mário de Andrade e Sergio Milliet, polêmicas amistosas e construtivas, num exemplo de compostura e amor pela verdade que não é frequente no gênero"13 (CANDIDO p. 99). Essa prática diária favorecia o confronto e o entrelaçamento de ideias e uma compreensão maior do tecido heterogêneo e diverso da sociedade brasileira, alvo de suas preocupações de pesquisador. Bastide manteve correspondência constante com intelectuais, escritores, poetas e políticos brasileiros e estrangeiros. Alguns deles durante anos e até décadas, outros por toda a vida. Muito dessa correspondência confirma sua busca constante de estudioso, mostra o empenho e testemunha o seu desejo de conhecer as origens, percorrer os traçados das influências e das trocas. A mesma atividade crítica e de leitor infatigável presente em suas aulas, artigos e livros está também presente na sua prática epistolar. Lendo a correspondência que manteve com amigos e intelectuais, observamos que o seu objeto de pesquisa estava sempre presente - ele colocava-o sempre à prova -, acolhendo sempre a palavra do outro. A correspondência foi para Bastide um meio de contato, de aprofundamento de amizades, de troca de ideias e de debates sem fim, uma prática de escritura que marcou o seu percurso de pesquisador.

O debate que manteve com Câmara Cascudo através de cartas sobre o "desafio popular" pode ser um exemplo disso. Estudando-o em suas diversas variações, comparando-as com as existentes nas diferentes regiões do Brasil e até com a que teria identificado na África, Roger Bastide abre, através da prática epistolar, um debate sem fim com intelectuais brasileiros e, particularmente, com Câmara Cascudo ${ }^{14}$, "une guerre em dentelle"15.

$\mathrm{Na}$ obra autográfica de Bastide há uma forte presença de colaboradores, como se houvesse uma sociabilidade de criação, uma possibilidade de cooperação de saberes. Nos traços de sua escritura autográfica, ao individual se junta o coletivo. Esse atributo coletivo está presente não somente em cada um de seus livros, artigos e trabalhos, mas também, e de forma mais evidente, nos seus manuscritos. O contato concedido e a participação aco-

13 CANDIDO, Antonio. Roger Bastide e a literatura brasileira. Recortes. São Paulo: Companhia das Letras, 1993, p. 99-104.

14 As cartas de Cascudo enviadas a Bastide fazem parte do arquivo. Quanto às cartas de Bastide para Cascudo, encontrei um rascunho redigido no verso de uma das cartas de Cascudo a Bastide.

15 Ver o artigo "A presença de Câmara Cascudo nos manuscritos de Roger Bastide", de minha autoria em: Scriptoria III - ensaios de literatura. Natal: EDUFRN, 2008, p. 163-175. 
lhida geram a interlocução, revelando a conduta respeitosa do pesquisador para com o "outro" - seu objeto de estudo - e para com seus pares. Assim, nos registros produzidos na convivência do discurso antropológico e do diário pessoal entremeiam-se vozes de pesquisados e de pesquisadores, de tradutores e traduzidos, presentes nos estudos do antropólogo. Os textos, as notas de observações, as notas de leitura e de cursos, os desenhos, as tabelas, os registros documentais, as listas e a correspondência se complementam entre si enquanto produtos e prática de um trabalho coerente.

Após meses de trabalho, no decorrer dos quais percorri uma grande quantidade de títulos da rubrica Notes de lecture et de voyage, verifiquei também o conteúdo de outras rubricas existentes no inventário: Cours, Textes, Notes de cours e Correspondance générale ${ }^{16}$, Correspondance professionnelle, Correspondance avec les étudiants, Documentation générale, Documentation personnelle ${ }^{17}$. Ainda que tais rubricas não apresentassem as escrituras de campo ou apresentassem-nas subjugadas pela escritura epistolar e outras, a leitura de documentos e de inúmeras cartas permitiu-me uma melhor compreensão do desempenho de Bastide enquanto intelectual, professor e pesquisador. Em qualquer um desses papéis assumidos pelo antropólogo, uma conduta se destaca: a busca de interlocução com outros pesquisadores para compartilhar sua experiência. Trata-se de um "savoir-faire" que se efetiva numa dinâmica dialógica que, interagindo com os "outros", cria processos, por meio dos quais sujeitos possam também falar sobre si e por si mesmos como sujeitos do discurso.

\section{Entre as viagens: um encontro}

Depois da Segunda Guerra Mundial, entre suas viagens, Bastide conhece Pierre Verger, colaborador e amigo que estará regularmente ao

16 Correspondência de Roger Bastide e Claude Lévi-Strauss. Total de 17 cartas e alguns cartões (de 1944 a 1972). A leitura só foi possível graças à autorização dada pelo próprio Lévi-Strauss, por meio de uma carta manuscrita. Roger Bastide e Pierre Verger - 44 cartas - leitura autorizada pela Fundação Pierre Verger (Salvador/Bahia - Brasil).

17 Fiz a leitura de um número significativo de cartas de intelectuais, antropólogos, políticos, escritores e de poetas brasileiros e estrangeiros. Entre eles, Mario de Andrade, Carlos Drummond de Andrade, Gilberto Freire e Manuel Bandeira. 
seu lado em suas viagens de estudos. Em 1948, Bastide viaja para o sul do Brasil, Uruguai e Argentina, e em julho de 1951 vai para o Nordeste brasileiro. Durante a sua permanência na região Nordeste, Bastide é iniciado no candomblé sob o signo de Xangô. É neste momento também que ele planeja sua volta para a França, pois um cargo de diretor de estudos na École Pratique des Hautes Études lhe foi proposto por Lucien Febvre. Em 1952, realiza uma viagem pelo planalto central do Brasil. De volta a Paris, em novembro do mesmo ano, a Unesco lhe encomenda uma pesquisa sobre os estudantes africanos na França, que ele realizará com Pierre Verger. Em 1954, durante sua estada no Brasil, parte para Recife no mês de agosto. Entre 1955 e 1959, enquanto prepara sua tese, Bastide escreve muito, alguns de seus textos mais importantes datam dessa época.

1958: rumo à África

“Les navires négriers transportaient dans leurs flancs
sonores non seulement le fils de la Nuit, mais encore
les dieux, les orixás de bois, de fleuves et du ciel afri-
cain. [...] C'est ainsi que s'est créé le candomblé et il
s'est maintenu, à travers bien des résolutions, jusqu'à
nos jours".
Roger Bastide - Autres textes - Candomblé da Bahia
- BST2. A7-01.09.

Em 1958, de 13 de julho a 22 de setembro, Bastide parte em missão pelo Instituto Francês da África Negra, em Daomé (atual Benin) e na Nigéria, para descobrir algumas das fontes das religiões do Brasil. Sobre esta viagem de estudo, Bastide nos revela seus objetivos: "Pretendo não somente assinalar essas diferenças como ver se pego a toada originária ou o que dela restar na África [...]"18. Pierre Verger é quem prepara no local a sua viagem:

18 Este texto é parte da carta-resposta a René Ribeiro. 
12 Juillet - Voyage avion - Paris - Kotonou.

13 Juillet - Arrivée Kotonou - Verger m'attend avec camionnette IFAN $N^{19}$. Beau temps, mais nuages vers le soir. Départ pour Ouidah $^{20}$ (40 km environ) un diner chez M. Bisson, maire ${ }^{21}$. (Cahier de terrain de Bastide)

Durante a sua estada na África d'Oeste, Bastide vai contar com a participação do antropólogo Pierre Verger em seus deslocamentos de estudos. A presença do antropólogo se faz por meio de formas mais ou menos evidentes ou mais ou menos intencionais. Trata-se às vezes de uma presença discreta, objetiva e, neste caso, anunciada por meio de notas, lembretes e/ou citações breves, ocupando timidamente as margens do suporte e da escritura, mantida sempre em total convivência com o autor. Outras vezes, a presença dessa voz entra sorrateiramente, mas de forma contundente penetrando a escritura, surpreendendo algumas vezes o "autor" e desafiando o leitor/pesquisador.

Dentre todas essas formas de presenças há ainda aquela que, apesar do livre acesso concedido e do pacto estabelecido, escapa do controle e desorienta o pesquisador que se vê diante de um texto a quatro mãos. Ao mesmo tempo em que a escritura revela e exibe a olhos nus essa presença, nem sempre a identidade do "outro" está evidente. Os detalhes se acumulam e pistas indicam probabilidades, mas a comprovação desses sinais e traços somente será alcançada com o conhecimento aprofundado da obra manuscrita dos autores. Assim, às escondidas ou por meio de jogos mais ou menos dissimulados, realizados pela interferência e pela interlocução, desvenda-se a presença cúmplice e marcante, de caráter reflexivo e científico, de Pierre Verger na escritura de campo de Bastide. Esta viagem de estudo não só sedimentou a amizade, mas, e principalmente, também permitiu aos dois construírem uma história daqueles que: "On appelle Brésiliens au Dahomey et au Nigéria les descendants des anciens esclaves du Brésil qui, après la suppression du travail servile, sont retournés au pays de leurs Pères" (BASTIDE, Roger).

19 IFAN: Institut Français de l'Afrique Noire.

20 Ouidah $=$ Uidá.

21 Neste texto, a escritura de Roger Bastide está em itálico. 


\section{Daomé e Nigéria: os cadernos de campo de Bastide ${ }^{22}$}

Considero que a escritura dos cadernos de campo é uma prática que o antropólogo concebe no campo como uma ação. A escritura de campo deve organizar uma relação entre o "eu" e o "outro". O sujeito scriptor deve distinguir bem o "eu" e o "outrem", articulando o tempo da escritura, o tempo dos fatos observados, o tempo de uma história de vida e o tempo social.

Roger Bastide tem uma problemática central que vai acompanhá-lo durante toda a sua vida e que se refere aos contatos culturais. O campo de observação será sempre a Europa, o Brasil e a África, mas o Brasil será para ele o ponto nevrálgico das trocas dos sistemas simbólicos entre a Europa e a África. Bastide parte para a África Ocidental durante o verão europeu de 1958; vai para Daomé (atual Benin) e para a Nigéria. Para essa viagem de estudos, privilegiará as questões étnicas, o social e a estética, pois sempre defendeu o princípio de que o enigma étnico e a condição social intervêm na elaboração das obras e nos rituais religiosos. No transcurso dessa viagem, fará observações de campo num contexto de origem com o objetivo de obter uma compreensão adequada das fontes e dos "fluxos e refluxos" 23 dos rituais religiosos entre o Brasil e a África Ocidental.

\section{Estrutura dos cadernos}

De acordo com as indicações feitas por Roger Bastide, os cadernos de campo (viagem à África, 1958) do antropólogo possuem a seguinte estrutura:

Caderno I - corresponde ao "Caderno de Viagens: Daomé e Nigéria I": um caderno cinza, de 192 páginas, denominado por Bastide de Mon Journal.

Caderno II - corresponde ao conjunto "Caderno de Viagem: Os brasileiros de Ouidah", constituído de três volumes: caderno azul-claro

22 Cf. nota 8 .

23 "Fluxos e Refluxos": essa expressão fas parte do título da obra de Pierre Verger: Flux et Reflux de la traite des négres entre le golfe de Béninb et Bahia de Todos os Santos. Paris: Mouton \& Co., 1996. $720 \mathrm{p}$. 
(rascunho) - 24 páginas - Brasileiros de Ouidah; caderno amarelo (rascunho) - 24 páginas - Brasileiros de Ouidah (forte português); caderno azul-escuro (rascunho) - 48 páginas - lista de brasileiros por bairro em Ouidah.

Caderno III - corresponde ao "Caderno de Viagens: Daomé e Nigéria II": um caderno Air France, com os Batismos em Agoue - 1846-1880 (na frente) e, sobretudo, a continuação de seu diário começado no caderno I (no verso). Neste artigo, analisaremos apenas aquele que Bastide chama de Mon Journal. Trata-se de seu caderno de notas, com muitos dados de observação do campo, mas também notas de leitura e notas pessoais. Conforme comentário sobre a estrutura dos cadernos, esse conjunto se distribui por dois volumes, o caderno cinza e o caderno Air France. A estrutura dos cadernos que apresento aqui retoma a organização estabelecida pelo próprio Bastide numa de suas folhas soltas, em que anota o conteúdo de cada caderno e como eles se organizam uns em relação aos outros.

Suporte/conteúdo: Mon Journal é um caderno quadriculado, em brochura, com uma capa de cartolina cinza - 192 páginas, de tipo escolar. Formato: $22 \mathrm{~cm}$ x 16,5 cm. O caderno foi paginado por Bastide e contém apenas escritura manuscrita. Cobriu-o com uma caneta esferográfica azul, numa letra minúscula, de difícil leitura. Serve-se do caderno empregando dois tipos de escrituras, profissional e pessoal, distribuídas da seguinte maneira ${ }^{24}$ :

- da página 1 à página 182 - escritura de campo - páginas entremeadas de anotações de leitura (numeradas pelo autor);

- a partir da página 183, ele escreve "Apêndices" (páginas não numeradas), a escritura profissional está menos presente; trata-se, sobretudo, de uma escritura pessoal.

Desde a primeira página desse caderno, temos a data: 12 de julho, sem especificação do ano. Embora, nessa etapa, minha análise não previsse uma abordagem genética, fui obrigada a recorrer à obra do autor ou à sua correspondência para desvendar certos elementos.

A segunda parte desse caderno - Apêndices - está dividida em:

I-Livros Lidos: uma lista de 44 títulos, nas duas primeiras páginas. 
Depois, um pequeno traço, que costuma marcar a organização do espaço da página nas anotações de Roger Bastide, seguido da seguinte notação:

Pesquisas sobre os mercados: Sr. Honoré Zinsou.

Pesquisas sobre os brasileiros: Sr. Pascal Houssou ${ }^{25}$.

II-Orçamento: apresentado em colunas com as seguintes rubricas: Datas; Receitas; Despesas; Saldo.

III-Compras: lista de 40 presentes, proveniência e preço. Depois, ao lado: para Métraux: 5 presentes - proveniência e preço.

$I V$ - Presentes: lista nominativa das pessoas, família, amigos e quantidade de presentes para cada um. Nota-se nesse apêndice a coexistência de dois tipos de escritura, apesar da predominância da escritura pessoal.

\section{Mon Journal}

O caderno I contém uma série de entradas regularmente datadas de 12 de julho a 5 de setembro. Desde a primeira página, notamos que mais uma vez os dois registros, pessoal e profissional, se cruzam e se confundem. Além da intromissão da escritura pessoal, aparecem interlocuções, diálogos e relações estabelecidos com obras, teóricos e pesquisadores. Desde o começo desse caderno, encontramos a presença de Pierre Verger. Temos frequentemente a presença de notas de leitura, desenhos e tabelas de dados. Nesse caderno I, Bastide faz constantemente referência a outros cadernos e a outras leituras e a outros dados. Tudo isso constitui sem dúvida um conjunto a ser decifrado e decodificado, lido e interpretado, pois num mesmo caderno coabitam práticas de escritura diferentes: a escritura de observação, a escritura especulativa, a escritura do "dia a dia", os desenhos, as questões e

25 Essas observações me deram a possibilidade de saber que, entre as cartas que Bastide registra em seu diário, algumas foram endereçadas aos seus alunos. 
hipóteses sobre os fatos observados. Portanto, embora o íntimo não ocupe o lugar central nesses cadernos, sempre se manifesta através de uma pequena frase escrita rapidamente e às vezes riscada, de um pequeno comentário, de uma comparação importante. Com efeito, o caderno destina-se a acolher diferentes práticas de escritura.

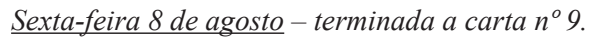

Festa de Oshum à Oshogbo.

Cf. A festa para O. De Joana de Ogun e numa certa medida também as festas de presente a Yemanjá no Brasil.

[...] Às 9h. Nós estamos na casa do rei Alapa. Ele instalou seu trono diante da porta da varanda [...]

Enquanto faz suas anotações, ele dá sequência a sua reflexão:

Ver no livro de V. O mito que explica esta festa de Oshun. Este mito é relembrado pela procissão do Rei ao rio, a cada ano, [...] Data fixada anteriormente que V. tinha calculado a partir do calendário Yorubá.

À margem de sua escritura de observação, Bastide anota:

$V=$ não há delegação d'llesha hoje (salvo 1 tambor e 2 ou 3 membros, mas não o Rei).

Uma nota mais pessoal:

Interrompido pela visita do Rei d'Ilobu que nos visita em retribuição à nossa.

Aliás, a casa onde nós moramos pertence a ele.

O antropólogo pode a priori exercer sua escritura de campo com a exclusiva preocupação de se servir da língua para suas necessidades concretas, num determinado contexto. É uma escritura que não prevê a existência de outro leitor além do próprio autor. Esse texto, com os dados 
que comporta, é indispensável para a composição de uma obra futura, mas a publicação dessa matéria-prima não parece ser considerada em nenhum momento pelo autor.

O que fascina e interessa Bastide é, sobretudo, o objeto que observa. É visível a sua preocupação em não perder nada, em estar atento e seriamente vinculado ao seu tema de estudo, em ver tudo, saber tudo, analisar tudo para entender, mas sem desvendar os segredos, como alguém que respeita os limites alheios.

Os cadernos e as folhas, bem como os documentos de apontamentos de campo, revelam concretamente seu caráter de pesquisador incansável. Nessa escritura há poucas correções. Alguns discursos são produzidos à medida que o autor observa e outros talvez um pouco depois. Estamos, pois, diante de um material híbrido. Percebe-se, no entanto, uma disciplina, uma objetividade, uma concisão e uma clareza nas anotações, mesmo se às vezes elas são difíceis de decifrar. O autor satura a página acumulando referências e notas dentro das notas. Vez por outra ele lista, monta inventários de seus artigos, de suas conferências, de seus livros e publicações. Cria um repertório dos textos de referência, às vezes acrescido de desenhos e/ou croquis. Embora o conteúdo de certas páginas comporte apenas observações de campo, estou convencida de que, em seu conjunto, esse caderno constitui todo um universo onde as diferentes escrituras estão em permanente interação.

Assim Bastide inicia seu caderno de campo:

\section{2 julho: viagem avião Paris-Cotonou ${ }^{26}$.}

É a abertura de um caderno de campo ou de um diário de viagem? Essa entrada poderia corresponder a um título. Imediatamente, constatei que o que estava em questão não era a viagem, mas o estudo, os dados de observações, as buscas que começam desde as primeiras linhas.

13 julho - chegada em Cotonou. Verger me espera com caminhonete IFAN. Tempo bom, mas trovoadas à noite. Partida para Ouidah (40 km aproximadamente), um jantar na casa do 
Sr. Bisson, prefeito. A casa me lembra estranhamente o Brasil: come-se fora, cada um se serve, entre as flores, as árvores, debaixo de uma mangueira. Paisagem um pouco recifense. Vários membros da "colonia francesa", brancos ou martinicanos, guianenses - De manhã, visita ao mercado - De tarde, visita ao bairro "brasileiro". Ensaio da "Burrinha"27.

Primeiro comentário pessoal:

muito bom.

Várias adaptações de palavras:

fazendaire, récifien.

A partir da metade da primeira página, uma breve descrição de sua chegada, mas já registrando a presença e a participação de Pierre Verger nessa viagem. Esse primeiro parágrafo contém um detalhe importante: a partir de agora, Bastide irá estabelecer relações com o que conheceu no Brasil. Isso reforça a problemática de seu estudo. Entre os exemplos apresentados acima, também podemos citar o sincretismo linguístico, adaptações de palavras da língua portuguesa.

Em seguida:

questões a serem resolvidas:

Seis questões seguidas de comentários parcialmente descritivos, depois uma presença discreta do "eu":

muito interessante ver [...].

Há um único asterisco à margem, na altura das questões a serem resolvidas; essa economia de meios é uma marca característica da escritura

27 Textos em português do Diário de Bastide, tradução nossa. 
de campo de Bastide. Depois das questões e dos comentários, prossegue seu raciocínio com a formulação de três hipóteses.

A escritura de campo de Roger Bastide se dá por meio de duas ações no que concerne às práticas de escritura. No mesmo caderno, coexistem a escritura nômade e a sedentária. Se o Caderno I pode ser dividido em duas partes - profissional (o "outro") e pessoal (o "eu") -, enquanto suporte podemos dividi-lo em suporte nômade e suporte sedentário.

Ainda em 13 de julho - No meio da página 2, à margem, um subtítulo:

$$
\text { À noite. }
$$

Em seguida, duas notas à margem:

Ver fotos Verger e (ver nome exato da reportagem Verger).

Reflexão e a referência constante de Bastide à sua experiência brasileira:

Mesma lentidão que no Brasil na preparação para sair. A saída e a ida para a cidade.

Depois, descrição/comentário escritos a posteriori, num espaço entre 13 e 14 de julho:

Problema: em que medida a cidade faz as diferentes etnias participarem da festa? Tenho a impressão (hoje, 15 de julho quando escrevo) que a festa = escolha de um grupo, e que os outros grupos podem apenas olhar, não participam. Segmentação muito distante de nós (e do Brasil).

Essa parte me indica que ele faz essas reflexões depois da observação dos fatos, donde as notas de 15 de julho. A construção do problema mencionado é, na verdade, produto de três dias de observação e provém de um cruzamento constante entre escritura nômade e escrita sedentária. À 
margem, há simplesmente um asterisco na frente do problema e a indicação de que o trabalho de Pierre Verger será importante para o estudo de Bastide:

Ver fotos de Verger.

Nesse caderno, será difícil encontrar alguma página sem referências bibliográficas. Página 4:

15 de julho - Ver caderno especial ${ }^{28}$ - cerimônia de Xangô.

Em seguida um quadro, uma tabela das visitas realizadas: nomes das pessoas, dos lugares, apontamentos. As tabelas com os dados de observação aparecem na mesma página, no mesmo dia, mas cada registro tem sua identidade. Desse modo, é possível reconhecer as duas ações em sua escritura: as observações e registros sistemáticos de campo e o balanço e reestruturação dos dados coletados.

Página 5: primeiro uma descrição da cerimônia - tenho a impressão de que ele está olhando enquanto escreve -, mas imediatamente faz comentários, anota que é preciso olhar outros cadernos e elabora questões.

Em primeiro lugar existência do poste central em torno do qual gira a roda das crianças (mulheres + sonhadoras (sonheuses) que os homens).

Bastide põe entre parênteses:

(ver desenho outro caderno).

Esta roda $=$ criança (1) várias filhas (2) - desenhos.

Os visitantes pertencentes a outras sociedades sentados sobre esteira (contudo, da sociedade de Xangô, ao menos em certas cerimônias, há uma filha de obalala) POR QUÊ??? caderno especial.

28 Após quatro páginas de escritura no caderno I, Roger Bastide indica a existência de um 
Destaque na página para a seguinte frase:

Enviar bibliografia para Verger: Livro América, Guiana Holandesa.

Conferência

V. sobre Morlen Revolts in Brasil.

Seguido dos comentários.

16 de julho (Quarta-feira) - Visita chefe de gabinete do substituto do governador - Banco - Compras diversas, visita IFAN - tesouraria (recebi 25.000 francos).

Aqui podemos destacar a presença da escritura-memória na elaboração de sua agenda.

Quinta-feira 17 de julho.

Ele resume o que fez.

Necessidade de compreender bem os dados obtidos em campo. Revisão e balanço - Bastide redimensiona novamente os dados. A escritura é feita fora do campo, pouco tempo depois, quando retoma a cerimônia que viu.

As notas de 15, 16, 17 e 18 de julho estão numa mesma página do caderno, mas são registros relativamente distantes e indicam a diversidade da escritura de Bastide. Nessa forma de construir seu discurso, concentra informações, agenda, comentário pessoal, notas de leitura, questões. Sem esquecer que, para cada questão, remete-se a obras ou a estudiosos, porque quer trocar ideias, confrontar os dados reunidos e compartilhar os resultados.

Sexta-feira 18 de julho: ir ao banco de manhã, se aberto, para pegar talão de cheques Feito (riscado). Em seguida:

NOTAS - Nigéria, 56, 1958.

As notas de leitura, muito rigorosas, obedecem sempre ao mesmo método: primeiro põe a página e depois as anotações de leitura, sem comentário pessoal, sem diálogo, estilo "ficha de leitura". 
Exemplo de escritura de agenda pessoal

\begin{abstract}
Manhã - Visita prefeito. Ausente - Passei banco - Passeio.
Tarde - Voltei para Sakete para assistir à visita de Xangô ao mercado (= o Xangô possuído) - Saída às 4h. Chega às 4:30h mais ou menos. Xangô faz visita ao Rei de Sakete, Ghedibo. Fora, diante da casa do Rei, na grande praça, o coro das filhas de Xangô canta e dança.
\end{abstract}

Em seguida, um desenho.

Descrição/anotação de leitura - p. 7 e p. 9.

Manhã - Visita prefeito - ausente - passei banco-passeio.

Anota:

Segundo Verger, Xangô (Ponto de vista de Verger) - ainda ficará nesse estado [...] por 2 dias e depois cerimônia de retirada de Xangô: farão ele deitar no chão e por uma espécie de passes longitudinais, farão Xangô sair (portanto, duração de 15 a 20 de julho - são 6 dias).

Esta noite - visita de Pascal para o estudo sobre os brasileiros. Sábado 19 de julho: descer ao porão.

Pascal é o estudante que aparece no apêndice do caderno $\mathrm{n}^{\mathrm{o}} \mathrm{I}$. Mais tarde, Bastide anotará seu endereço, certamente para escrever para ele. A prática epistolar faz parte do seu dia a dia, durante a viagem.

Na p. 102:

Quarta-feira - 20 de agosto - Carta $n^{\circ} 17$

Conversa ontem à noite com Pascal sobre a cerimônia análoga ao Loragun brasileiro. Eis as informações coletadas: [...].

Na p. 107:

Quinta-feira 21 de agosto, carta $n^{\circ} 18$ 
Bastide resume o que tinha esquecido de contar na véspera e acrescenta:

Hoje fui para Ouidah para estudar os brasileiros. Parada em Cotonou onde pego 25000 frs no banco.

Esqueci de dizer ontem que quando fizeram sair os iyaé [...].

A presença do verbo "dizer" aqui é um dos inúmeros exemplos da presença da voz na escritura de campo de Bastide. Fica evidente a presença de dois modos de escritura: oral e escrita. Nota-se a forte presença dos colaboradores de Bastide em seus escritos. Nos traços da escritura autógrafa de Bastide, ao individual acrescentam-se indícios do coletivo. A importância da correspondência pode ser comprovada num diálogo a quatro mãos e confirma mais uma vez o atributo coletivo solidamente ancorado em sua escritura. Há um momento em que Bastide começa a anotar a data sem o mês e as cartas (é possível adivinhar o mês seguindo a sequência das datas) passam a ser numeradas.

Ex: na página 25, ele anota:

Segunda-feira $28-{\operatorname{Carta~} n^{\circ} 1 .}^{2}$

Notas de leitura p. 27:

Terça-feira $29-$ Carta $^{\circ} 2$.

Manhã: Cotonou, [...] providências para a Nigéria. Mas só é possivel marcar uma hora para amanhã de manhã. Na volta, calor sufocante. Longa sesta [...] De tarde passei instruções para aquele que vai estudar os mercados. Verger o acompanha ao mercado de Porto Novo, para lhe explicar melhor o que é preciso fazer, conforme o plano que tracei. Mas estou cansado demais para acompanhá-lo.

Nome da pessoa que prepara um estudo sobre os mercados $=$ Honoré Zinsou.

Em seguida: Notas de leitura.

Sexta-feira 5 de setembro: Carta $^{\circ} 28$ (foto 3 ). 
As fotografias citadas são da obra de Pierre Verger (1995) ${ }^{29}$. As fotografias e as imagens são mais um meio de completar a pesquisa.

Notas deste último dia:

Acho que esqueci de dizer, a respeito de Yashime, que após peditório a Sra. da Silva fica com a caixa do altar nas 2 mãos [...]. Da Cruz, brasileiro de Almey = funcionário do IFAN.

Continuação: Notas de leitura e desenhos.

\section{Caderno de Viagens: Daomé e Nigéria II ${ }^{30}$}

Suporte/conteúdo: Caderno de tipo escolar, quadriculado, em brochura com 96 páginas. A capa do caderno traz a inscrição "Super G / Air France", talvez seja um caderno que pegou durante a viagem de avião. $\mathrm{Na}$ capa, leem-se as seguintes palavras: AGOUE (petit Popo), escritas por Bastide, depois Anecho com a letra de $\operatorname{Verger}^{31}$.

A letra de Verger também aparecerá na página 13 desse mesmo caderno $^{32}$.

$\mathrm{Na}$ contracapa do caderno, Bastide copia do documento (em consulta) a seguinte abertura:

Recebi do Sr. Andre da França a quantia de quatorze mil (...) vinte reis das obras de [...] que pratiquei p/a Costa da Africa e por ser verdade haver recebido a indicada quantia faço presente por mim assinado: Ba., 5 de Out. de 1844.

29 Essas fotos estão em Dieux d'Afrique, de Pierre Fátúmbí Verger. 1995.

30 (Cadernos de Viagens: Daomé e Nigéria II) BASTIDE, Roger. Ms. A continuação de seu diário (Caderno de Viagens I) e, sobretudo, dados de pesquisa. BST2.N6-03.02.

31 Essa identificação foi possivel depois da leitura das cartas de Verger a Bastide.

32 Essas cartas de Pierre Verger a Bastide foram encontradas na série Notas de leitura e de viagem. A Fundação Pierre Verger, em Salvador /BA, autorizou a leitura da correspondência de Pierre Verger a Bastide. 
Diferentemente do primeiro caderno, este é utilizado dos dois lados. $\mathrm{Na}$ frente, Bastide copia registros de batismos feitos em Agoué por padres negros de São Tomé residentes no forte português de Ouidah, acompanhado de algumas observações.

Em seguida, dá continuidade à cópia dos registros (que vai de 1846 a 1882) até a página 40 do caderno e acaba com a seguinte anotação:

\section{Não terminamos este segundo registro.}

No verso, Bastide retoma seu caderno de viagem, iniciado no caderno anterior:

Continuação de meu diário (III). Escreve ele na capa.

O número III parece indicar que se trata da terceira parte de seu diário. Contudo, na estrutura estabelecida por Bastide, no caderno número II não há nenhuma parte de seu diário, apenas as listas de brasileiros de Ouidah. É verdade, porém, que o caderno I termina em 5 de setembro e que este começa em 13 de setembro. No estado atual de minhas pesquisas, é difícil saber onde foram anotados esses oito dias de diário; talvez o "caderninho" de que falamos traga esclarecimentos quando o encontrarmos.

Roger Bastide começa esse caderno, paginado até o n 37 desse lado, com:

\section{Continuação de 13 de setembro.}

Em seguida, retoma suas notas de leitura:

\section{P. Hazoumi - 50 anos de apostolado no Daomé.}

Suas anotações de leitura, as quais ocupam as primeiras páginas do caderno, são rigorosas. Quando necessário, o autor não omite a página do livro. Em seguida, faz suas observações. 
A partir da página 3, retoma a numeração de suas cartas, dirigidas aos seus alunos, e também suas observações.

Domingo 14 de setembro - Carta $n^{\circ} 36$ (foto 12).

Mercados

I-Sujeira-

E, dois dias depois:

Terça-feira 16 de setembro. Carta ${ }^{\circ} 38$ e última.

(anuncia a última carta)

Destinatário: Sr. Emile Honoré Zinsou

A/C Sr. Semassa Paul

Imprensa Oficial

Porto Novo.

O diário prossegue até domingo, 21 de setembro, com notas e observações. Neste último dia, Bastide escreve:

Ontem à noite, chegada inesperada de Rangel, que pensávamos ir esperar em Cotonou, de manhã. Na volta do restaurante, aonde fomos com ele, chuva pesada (a pequena estação das chuvas está começando). Buscamos refúgio no IFAN, onde copiei de 1 bibliografia africana alguns livros que talvez eu venha a conhecer.

Segue-se a lista dos livros, com títulos e quantidade de páginas.

Depois de um traço que põe fim ao diário propriamente dito, da página 29 à página 37, copia, aparentemente a partir de um registro de estado civil, uma longa lista de nomes (207), repertoriando nascimentos, mortes e casamentos.

O último elemento da lista é: 
27-XII-55 - Cotonou, Morte de Vicencia, 21 anos Felix Etienne de Souza.

Em seguida, data esse dia:

Segunda-feira, 22 de setembro.

(p. 37), para encerrar o caderno. É também o fim da viagem, já que volta para a França no mesmo dia.

O pesquisador precisa saber como fazer uso da diversidade de escrituras e estabelecer a continuidade de uma história, que não é nem ficcional nem pessoal. Contudo, no caso dos antropólogos de campo que se dedicam a escrever para registrar a observação do outro, o tempo, o contexto e a história são tidos como uma questão em si.

Em ambos os sentidos, o exame dos suportes utilizados - folhas ou cadernos -, bem como o exame da escritura profissional de Bastide, mostra que eles estão sempre entre a continuidade e a descontinuidade. Mais uma vez, o pesquisador tem de entrever, no cruzamento das práticas de escritura, os cruzamentos que concernem ao tempo, ao contexto e à história.

\section{A escritura de campo, itinerário de um antropólogo}

Uma boa articulação entre a prática, o gênero escritural de campo e o suporte que o recebe e que normalmente se constitui a partir de uma exigência, a da continuidade textual, parece descartar a priori o uso de folhas soltas. Para Bastide, porém, todas estas eram questões de menor importância.

No que concerne às anotações que Roger Bastide fazia em campo, nem os cadernos de campo garantem a continuidade dessa prática. Os cadernos não são como uma agenda onde temos um espaço por dia. A página do caderno é livre e pode ser utilizada de acordo com a vontade de quem escreve. Os cadernos acolhem uma escritura cotidiana. Contudo, essa escritura acompanha uma atividade que inclui deslocamentos. E, nesse caso, podemos prever a presença de uma escrita heterogênea e às vezes irregular. Para ele, é pela continuidade/descontinuidade das práticas de escritura e 
pela utilização de suportes variados que se pode chegar a uma continuidade. Uma continuidade conseguida, a meu ver, graças a uma grande quantidade de digressões.

A principal riqueza desses cadernos de campo não está na sequência de fatos, mas nas mudanças de direção, nos comentários e, é claro, nos diálogos que o etnólogo consegue estabelecer com seus parceiros. $\mathrm{O}$ discurso de observação estará no cruzamento do "eu" com o "outro" através de uma interpretação do tempo da escritura e do tempo social.

Bastide é alguém que quer registrar tudo, que raciocina e se coloca o tempo todo questões, inclusive enquanto está fazendo anotações. Às vezes, ele se detém para anotar uma pergunta ou um comentário. Ao mesmo tempo, é um homem que faz inventários de tudo, de seus artigos, leituras, livros, publicações etc. Acumula listas de obras, de nomes de pessoas e de amigos.

Sabemos muito bem que os escritos cotidianos do antropólogo, como aqueles que encontrei nos cadernos da viagem ao Daomé e à Nigéria, têm, antes de tudo, um valor instrumental para o estudioso. Diante da diversidade da escritura, essas anotações de campo fazem ressurgir, de tempos em tempos, no meio do discurso, um "eu". Um "eu" que se esconde e às vezes retorna timidamente, quase em solilóquio: "muito interessante", ou transformado em "não terminamos este registro", ou um "eu" que, na verdade, é coletivo. Para falar da presença de uma voz que se manifesta na primeira pessoa, a expressão mais correta no caso de Roger Bastide é sem dúvida: "o eu é um povo" (CIXOUS, 2002, p. 26).

Essa multiplicidade de "eus" que podemos notar em Bastide talvez se explique pelo fato de que, diferentemente de alguns antropólogos que foram para outros países, ele não está sozinho na África - faz essa viagem com Verger.

Em parte, talvez seja por esse motivo que Bastide só se entrega muito raramente a confidências pessoais em seu diário e prefira se concentrar nas suas dúvidas de estudioso. Quer achar um fio condutor na comparação de dois mundos, quer entender as fontes, busca esta que pode até provocar certa angústia. Para viver as crises da aprendizagem e melhor compreender esse ritual, inicia-se nele. Quis estar à altura, resolver os problemas como homem, mas também sempre como criador - com a paciência necessária para esboçar seus desenhos. Não há muita introspecção, o que há é o testemunho de um compartilhamento discreto. 
Roger Bastide levava a objetividade ao extremo para deixar sair o “eu” plural de que é portador. Seu método e seus procedimentos vão nesse mesmo sentido, recorrendo à teoria que ele coloca seriamente no meio da narrativa cotidiana.

Essas mesmas anotações de campo - balanço de um dia de observações -, que seguem a organização de uma escritura diária, não coincidem exatamente com a noção de "diário íntimo", nem com a de "diário de viagem" ou de "caderno de viagem", nem mesmo com a de "diário de bordo".

Bastide vai recolher um corpus que reúne mitos, relatos, expressões típicas e fatos folclóricos. No entanto, não podemos dizer se os cadernos de campo são construídos com o rigor que em geral é usado para os dados quantitativos e estatísticos; preserva sem dúvida algo desse rigor fazendo escolhas. Por exemplo, sempre numera as páginas dos cadernos, mas não se preocupa muito com a data, que muitas vezes está incompleta. A unidade temporal e escritural segue uma dinâmica totalmente pessoal.

Embora eu tenha observado certa discrição no tocante ao "eu", a presença de um scriptor-autor é bastante evidente. De qualquer maneira, as escrituras de campo de um dia de observações excedem obrigatoriamente a estrita esfera das observações antropológicas.

Nesse mesmo sentido, a escritura profissional de campo de Roger Bastide não é a de um escritor profissional e tampouco pode ser identificada com a do diário íntimo. Apesar da presença de alguns aspectos característicos desse tipo de registro, é simplesmente uma escritura que segue uma dinâmica em que a aparente descontinuidade permite entrever a diversidade do campo. Uma escritura que se desloca de um lado para o outro instituindo ao mesmo tempo, para aquele que a estuda, a natureza particular desses manuscritos, que não obedece nem a uma disposição coerente nem à continuidade exigida por outras práticas de escritura.

Apesar da falta de interesse pelo suporte, talvez haja ainda assim uma escolha, ao menos no que se refere aos cadernos. Diria que, nesse caso, Roger Bastide parece preferir os suportes mais acessíveis e mais simples possíveis. Entre os cadernos de campo de Bastide examinados, dois levam na capa a antiga denominação de "rascunho" e na capa de um outro vemos a publicidade da Air France. Em suma, todos os cadernos são cadernos escolares. A escolha desse tipo de caderno pode explicar a posição do antropólogo perante outrem; segundo Pierre Verger, ele "sabia se tornar o outro com um 
humor saboroso" (VERGER, 1994), e essa escolha certamente amarra a diversidade da escritura ao mesmo tempo em que estabelece a relação entre o "eu"/escritura pessoal e o "outro"/escritura profissional. Nesse sentido, diria que os detalhes dos modos de organização e dos suportes não poderiam ser os mesmos dependendo do tipo de escritura praticada.

Para Roger Bastide, não existe suporte privilegiado para a escritura - tudo serve para a escritura de campo. Ao abandonar o suporte em favor do texto, outras lógicas, outras práticas, outras representações ganham visibilidade, e o estudioso permanece sempre fiel a seu objeto de estudo sem ignorar as relações entre o ritual (observado) e a vida cotidiana. Sua escritura de campo revela que ele se coloca na situação de observador sem se afastar; ao contrário, quer assimilar todos os dados, inclusive as emoções.

A escritura dos cadernos de campo dessa viagem à África não tem um fechamento, um caderno nos leva a outros cadernos numa dinâmica de multiplicidade de dados, tanto aos cadernos já encontrados como, sem dúvida, àqueles que ainda falta descobrir.

Mas há um outro aspecto do Candomblé que não é menos importante e que chamou a atenção dos romancistas do Nordeste, é seu aspecto estético. A religião e a arte, que se separaram em nossa cultura ocidental, aqui, ao contrário, se casam em líricas bodas, e, embora seja previsível que um dia o elemento religioso do candomblé desaparecerá, esperamos que o brasileiro conserve a herança de beleza que os negros transplantaram para a sua nova pátria.

Era nisso que eu pensava dentro do carro que me conduzia, junto com alguns amigos, para o terreiro de Joãozinho da Gomea. (texto datilografado, correções manuscritas.)

Roger Bastide TEXTES

Autres Textes

[Candomblés de Bahia] BST2. A7-01.09 


\section{Referências}

BAKHTIN, M. (Volochinov). Marxismo e filosofia da linguagem. 6. ed. São Paulo: Hucitec, 1992. 196 p.

BIASI Pierre-Marc de. Carnets de travail. Edition critique et génétique établie par Pierre-Marc de Biasi. Paris: Balland, 1988. 1000 p.

et al. Carnets d'écrivains. Paris: Éditions du Centre National de la Recherche Scientifique, 1990. 253 p.

CANDIDO, Antonio. Roger Bastide e a literatura brasileira. Recortes. São Paulo: Companhia das Letras, p. 99-104, 1993.

CIXOUS, Hélène. "Variations autour de moi". Magazine Littéraire. Paris, n. 409, maio/2002.

CHARTIER, Roger. Culture écrite et société. L'ordre des livres (XIV-XVII). Paris: Albin Michel, 1996.

. Écrits intimes. Magazine Littéraire, Paris, n. 252-253, p. 18-108, avril/1988.

ELIAS, N. Engagement et distanciation. Paris: Pocket, 1993. 258 p.

. La societé des individus. Paris: Fayard, 1997.

FABRE, Daniel. Par écrit. Ethnologie des écritures. Paris: E.H.E.S.S. 393 p.

FOUCAULT, Michel. L'herméneutique du sujet. Paris: E.H.E.S.S./Gallimard/Seuil, 2001, 540 p.

GADAMER, H-G. L'Actualité du Beau. Aix-en-Provence: Alinéa, 1992. 209 p.

. Verité et Méthode: les grandes lignes d'une herméneutique philosophique. Paris: Seuil, 533 p.

GEERTZ, C. Ici et là-bas - L'Anthropologue comme auteur. Paris: Métailié, 1996. $147 \mathrm{p}$.

GOODY, J. Entre l'oralité et l'écriture. Paris: PUF, 1994. 323 p.

GRADHIVA. Revue d'histoire et d'anthropologie. (dossier: archives et anthropologie) Paris: Éditions Jean-Michel Place, n. 30/31, 2001/2002.

HEBRARD, Jean. Tenir un journal. L'écriture personnelle et ses supports. Cahiers IRTM. Paris, n. 20, p. 9-50.

JAUSS, H. R. Pour une esthétique de la réception. Paris: Gallimard, 1978. 
LECARME, J.; LECARME-TABONE, Eliane. L'autobiographie. Paris, 1997. 313 p. LEIRIS, Michel. L'Afrique fantôme. Paris: Gallimard, 1981. 656 p.

LEJEUNE, Ph. Le Moi des demoiselles. Enquête sur le jounal de jeune fille. Paris: Seuil, 1993. . Pour l'autobigraphie. Paris: Seuil, 1998. . L'autobiographie en France. Paris: Armand Colin, 1998, 192 p. . Bibliographie - des etudes en langues française sur la literature personnelle \& les récits de vie. Paris: Université Paris X, ritm22, 2000. 113 p. . Je est un autre. Paris: Seuil, 1980. 328 p. . Écrire sur soi. Magazine Littéraire, Paris, n. 367, juillet-août/1988. p. 76. et al. L'autobiographie. Poétique, Paris: Seuil, n. 56, nov./83. p. 417-484.

LES ECRITURES DE L'INTIME - La correspondance et le journal. Actes du colloque de Brest-23-24-25 oct. 1997 (testes rassembles et présentés par Pierre-Jean Dufief), Paris: Champion, 2000. 296p.

LÉVI-STRAUSS, Claude. Tristes Tropiques. Paris: Plon. 1955. 504 p.

MALINOWSKI, B. Journal d'ethnographie. Paris: Seuil, 1985. 320 p.

MAUSS, Marcel. Manuel d'ethnographie. Paris, Payot, 1947.

MORIN, Edgar. Journal d'um livre (juillet 1980/août 1981). Paris: Inter Editions, 1981. 229 p.

PETRUCCI, Armando. Jeux des lettres. Formes et usages de l'inscription en Italie $11^{\grave{e}}-20^{\grave{i}}$ siècles. Paris: E.H.E.S.S. 1993. 245 p.

RICOEUR, Paul. Temps et Récit - 3. Le temps raconté. Paris: Seuil, 1985. 533 p. . Teoria da interpretação. Lisboa: 70, 1976.

VERGER, Pierre. Flux et reflux de la traite des nègres entre le golfe de Bénin et Bahia de Todos os Santos. Paris: Mouton \& Co., 1968. 720 p. . Fátúmbi. Dieux d'Afrique. Paris: Revue Noire, 1995.

Recebido em abril de 2010. Aprovado em abril de 2010. 